\title{
PELATANTHERIA WOONCHENGII, A NEW ADDITION FOR THE ORCHID FLORA OF VIETNAM
}

\author{
Vuong Ba Truong ${ }^{1,4}$, Tam Quang Truong ${ }^{1}$, Khang Van NGuyen $^{2} \&$ Jim Cootes $^{3}$ \\ ${ }^{1}$ Institute of Tropical Biology - Vietnam Academy of Science and Technology, 85 Tran Quoc Toan, \\ Dist. Ho Chi Minh City, Vietnam \\ ${ }^{2}$ Number 735, Cai Von district, Binh Minh town, Vinh Long Province, Vietnam \\ 37 Bronte Place, Woodbine, NSW, Australia. 2560 \\ ${ }^{4}$ Author for correspondence: bavuong2019@yahoo.com
}

\begin{abstract}
Pelatantheria woonchengii is a new record for the orchid flora of Vietnam. This species was previously misidentified as Pelatantheria ctenoglossum, as both species are present in Vietnam. The illustration, description, distribution and comparison with the closest species in Vietnam are included. An updated identification key for all Vietnamese members of the genus Pelatantheria is presented.
\end{abstract}

KeY wORDS: new record, Orchidaceae, Pelatantheria woonchengii, Vietnam

The genus Pelatantheria Ridl. includes eight accepted species (Govaerts et al. 2017). In Vietnam four species are recorded by Seidenfaden (1992), and Averyanov and Averyanova (2003): Pelatantheria ctenoglossum Ridl., P. eakroensis Haager, P. insectifera (Rchb.f.) Ridl., and P. rivesii (Guillaumin) Tang \& F.T.Wang. The first author had the opportunity to study some specimens of P. ctenoglossum that he collected, and other Vietnamese specimens from his own collection. After closely examining these specimens, he realized that they present some morphological differences from the typical P. ctenoglossum. According to O’Byrne (2009), P. woonchengii P.O'Byrne, previously unrecorded for the flora of Vietnam, is a closely related species that looks very similar to $P$. ctenoglossum. The main differences between the two taxa are described below. With the inclusion of $P$. woonchengii, the number of Pelatantheria species recorded in Vietnam increased to five.

Materials and methods. The description presented hereafter is based on Vietnamese material found in Khanh Son district, Khanh Hoa province, supplemented with other specimens from the senior author's private collection, originally collected in the Daklak province, Vietnam. The measurements and description were prepared from living plants. Herbarium material was preserved in $70 \%$ ethanol and stored at VNM herbarium. All the photos were taken with a Canon 600D fitted with a EF-S $60 \mathrm{~mm}$ f/2.8 Macro USM lens. Terminology for the morphological description follows Beentje (2012).

\section{TAXONOMIC TREATMENT}

Pelatantheria woonchengii P.O'Byrne, Malayan Orchid Rev. 43: 98.2009 (Figure 1).

TYPE: Thailand. Cult. at Woon Leng Nursery (Singapore), O'Byrne PX450 (SING!)

Creeping epiphyte herb. Aerial roots, occasionally branched, produced along stem. Stem to over $30 \mathrm{~cm}$ long, slightly compressed. Leaves distichous, thick, elliptic, concave, obtuse, slightly unequally bilobed, channeled along the midvein, 2.0-2.5 $\times$ 0.9-1.0 $\mathrm{cm}$. Inflorescence axillary along the stem, $c a .1 \mathrm{~cm}$ long, peduncle short, slightly compressed, $c a .2 \mathrm{~mm}$ long, covered by 3 tubular bracts; rachis thicker than peduncle 7-8 mm long, 1-2 flowered; floral bract triangular, acute, ca. $2 \mathrm{~mm}$ long. Flower spreading, yellow striped with red on petals and sepals, the labellum yellow, the spur greenish-yellow. Dorsal sepal ovate, obtuse, ca. 4-5 × $3 \mathrm{~mm}$. Lateral sepals oblique, elliptic, sub-acute, $c a$. 6-7 $\times 3 \mathrm{~mm}$, with a distinct abaxial keel along the midvein. Petals thinner 


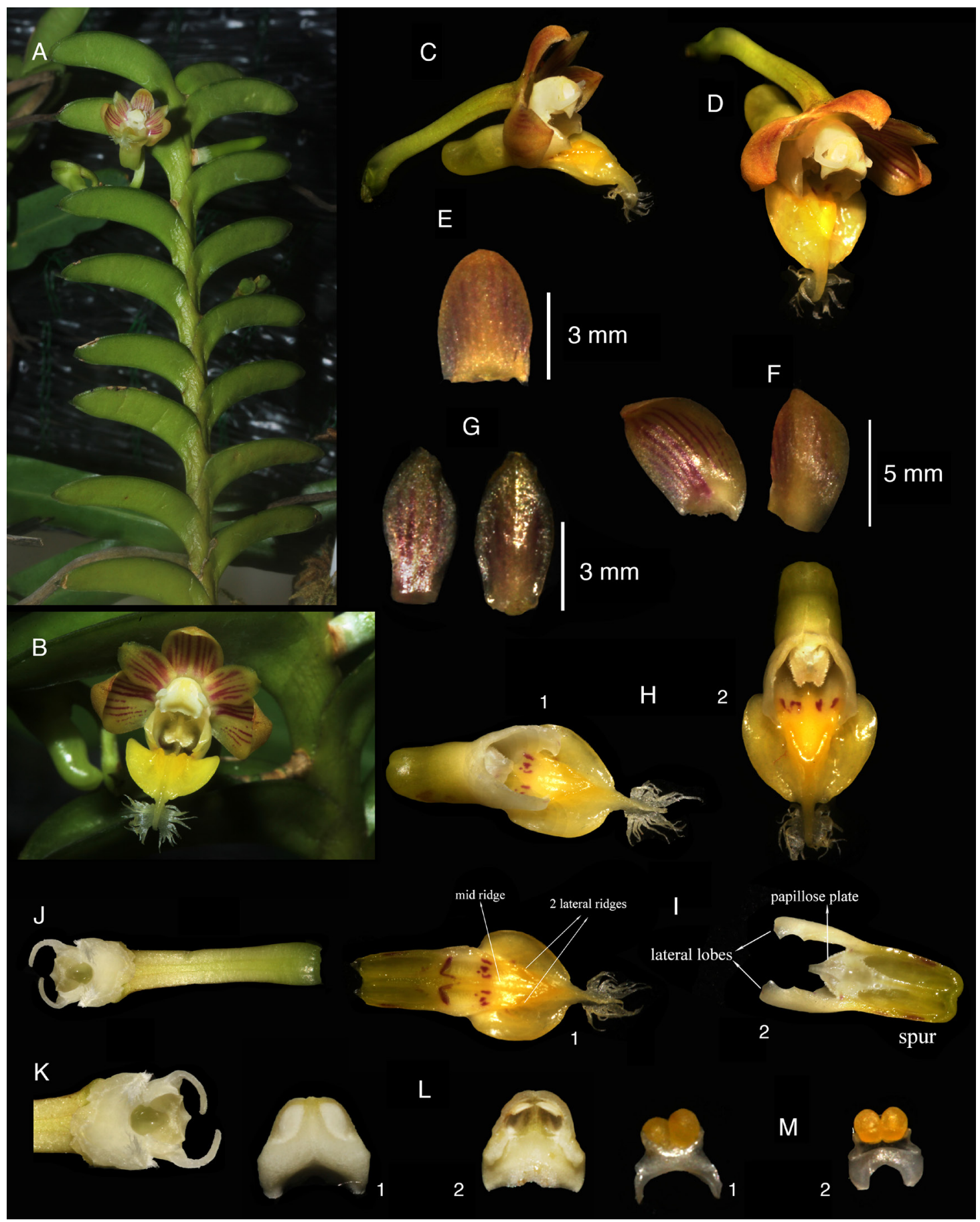

Figure 1. Pelatantheria woonchengii. A, habit. B, flower in frontal view. C, flower in side view. D, flower in upper view. E, dorsal sepal. F, lateral sepals. G, petals (abaxial and adaxial views). H, labellum with spur in adaxial (1) and frontal (2) views. I, mid lobe with spur, the lateral lobes removed (1) and present (2). J, column and pedicel. K, column. L, anther cap in frontal (1) and dorsal (2) views. M, pollinarium in frontal (1) and dorsal (2) views. Photo and drawing by Truong Ba Vuong from $B V 300$. 


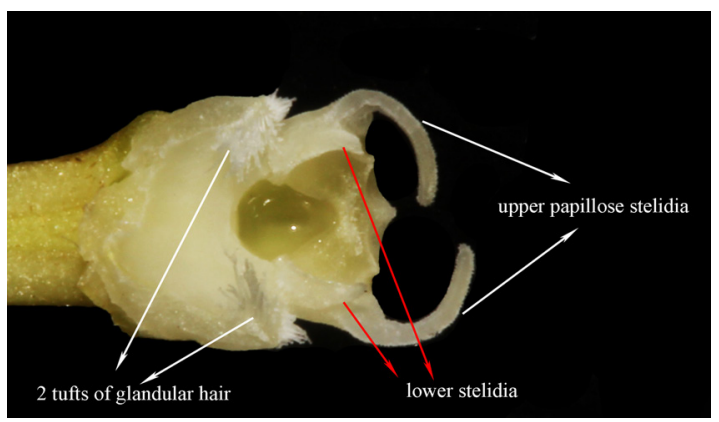

FIGURE 2. Pelatantheria woonchengii, detail of the column. Photo and drawing by Truong Ba Vuong from $B V 300$. Right, Figure 3. Ridges on labellum of Pelatantheria woochengii. Drawn by Truong Ba Vuong from $B V 300$.

than sepals, narrowly elliptic, sub-acute ca. $5 \times 2 \mathrm{~mm}$. Labellum 3 lobed, spurred, immobile, ca. $12 \mathrm{~mm}$ long (from tip of spur to tip of mid lobe); spur ca. $4 \mathrm{~mm}$ long, apex rounded, truncate, emarginate, slightly curved forward; lateral lobes erect, triangular, $c a .3 \times 2$ $\mathrm{mm}$; mid lobe broadly ovate to suborbicular, rounded, the margins slightly curved forward, 6-7 $\times 5 \mathrm{~mm}$ wide, the apex with an appendage $2 \mathrm{~mm}$ long and tufts of white hairs on the sides of apex; provided with 3 keels continuous from the ridge of spur septum, the central one lower than the lateral keels, fused on the middle of mid lobe into one narrower keel connecting with the apical appendage; spur provided on the floor with a median ridge, create the septum of spur and dividing it into 2 halves; the sidewall callus and the callus on the floor forming a backwall, laminar, ovate, papillose, T-shaped callus ca. $1.5 \mathrm{~mm}$ long. Column stout, $c a$. $2 \mathrm{~mm}$ long, provided at the base with 2 tufts of white glandular hair on each side, the apex with 2 pairs of lateral stelidia, the upper two incurved, papillose, embracing the anther cap, the other two shorter, oblique. Anther cap triangular. Pollinia 4, in two pairs, subglobose. Ovary (with pedicel) $1.1 \mathrm{~cm}$ long, the

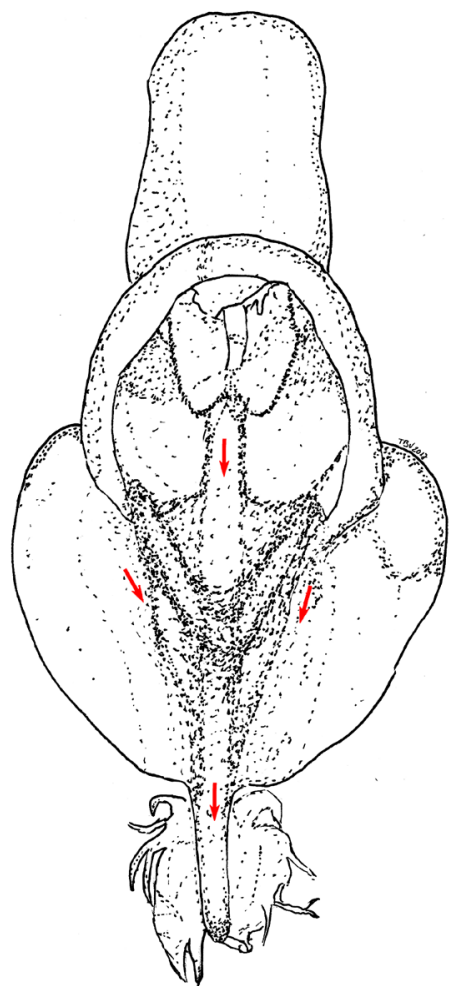

ovary straight, the pedicel slightly up curved. Capsule not seen. (Fig. 2-3).

Flowering time: From mid-October to late November.

Distribution: Khanh Son district (Khanh Hoa province), Daklak, Ninh Thuan. Peninsular Malaysia (Pahang), Thailand.

Specimen examined: Khanh Son District (Khanh Hoa province) $B V 239$ (VNM). Daklak province, flowered in the private collection of the senior author, $B V 300$ (VNM). Without specific locality, Nguyen Van Khang s.n. (Photo).

TABle 1. Comparison of the main differences between Pelatantheria woonchengii and similar to P. ctenoglossum.

\begin{tabular}{l|l|l}
\hline & \multicolumn{1}{|c}{ Pelatantheria ctenoglossum } & \multicolumn{1}{c}{ Pelatantheria woonchengii } \\
\hline $\begin{array}{l}\text { Callus on } \\
\text { midlobe }\end{array}$ & $\begin{array}{l}\text { Labellum with 3 keels, mid keel lower than 2 side keels, } \\
\text { 3 keels jointed to form a high keel in middle of mid lobe } \\
\text { and then compress into single narrow keel connecting } \\
\text { with labellum apex. }\end{array}$ & $\begin{array}{l}\text { "Mid lobe with large yellow callus...”, according } \\
\text { to Seidenfaden (1992); “...disk thickened and } \\
\text { cushion-like centrally, waxy”, according to Chen, } \\
\text { \& Wood (2009). }\end{array}$ \\
\hline Column foot & \begin{tabular}{l} 
Two tufts of hairs for each side \\
\hline
\end{tabular} & One tuft of hairs for each side \\
\hline
\end{tabular}



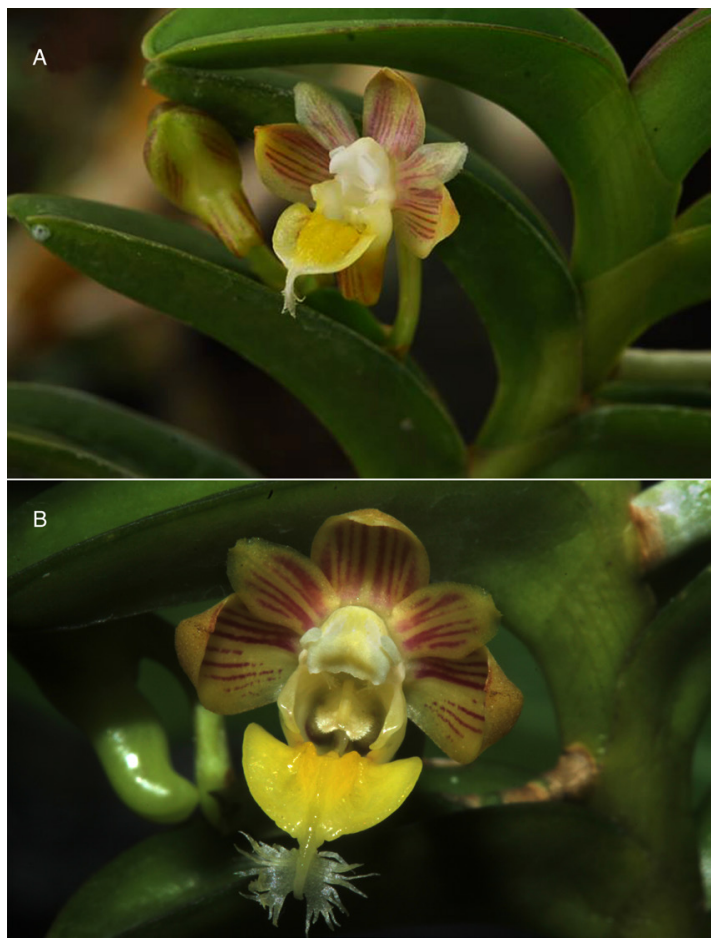

Figure 4. Species of Pelatantheria. A. P. ctenoglossum Ridl. (Photo by Chu Xuan Canh) and B. P. woochengii P.O'Byrne (photo by Truong Ba Vuong).

Pelatantheria woonchengii looks very similar to $P$. ctenoglossum and is misidentified in Vietnam. Below is the comparison of the two species (Table 1, Fig, 4).

There are 2 flower forms of $P$. woochengii found in Vietnam. The first one is described above. Another form (observed in the collection of the second author) is striped with red and has a lower number of stripes (Figure 5).

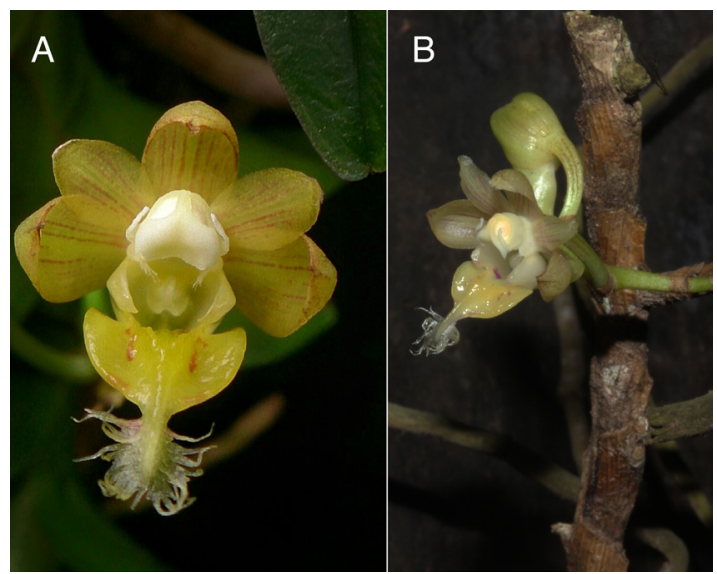

FIgURE 5. Specimens of Pelatantheria woonchengii with fewer reddish stripes. A, photo from theprivate collection of Nguyen Van Khang; B, photo of $B V 239$, collected by the senior author in Khanh Son district (Khanh Hoa province). Photo by Truong Ba Vuong.

Pelantantheria woochengii has recently been sold through the Internet in the Vietnamese market of wild orchids, at a very cheap price. Many populations of the species were destroyed by overcollection.

ACKNOWLEDGMENTS. The authors would like to thank to the reviewers for their critical suggestions that were helpful in improving the manuscript. The authors would like to sincere gratitude to Peter O'Byrne for his help in confirming the identify of Pelatantheria woonchengii and his fruitful discussion regarding the key. Thanks also go to Mr. Mark Arcebal Naive and Mr. Chu Xuan Canh for their kindness suggestions and excellent photos. The studies resulting in this paper were funded and supported by Institute of Tropical Biology (ITB) Ho Chi Minh City, Vietnam.

\section{Artificial identification Key to the Vietnamese SPeCies of Pelatantheria*}

1a. Pollinia 2, without hairs on column, short and thin appendage without projection on labellum apex

P. eakroensis

1b. Pollina 4

2a. Midlobe of labellum smooth, without projection on midlobe apex

3a. Midlobe with unclear central thickening, without or unclear hairs on column

3b. Midlobe with single mid ridge, dense white glandular hairs on column apex

P. insectifera

P. rivesii

2b. Midlobe of labellum with prominent yellow calli or warty cushion callus, with projection on midlobe apex

4a. Midlobe of labellum with 3 yellow calli, 2 tufts of hairs on each side of column ......... P. woochengii 4b. A broad warty yellow callus nearly covered midlobe, 1 tuft of hairs on each side of colum

P. ctenoglossum

* Based on data from Seidenfaden (1992), Haager (1993), Averyanov (1994), O’Byrne (2009), Chen and Wood (2009). 


\section{LiTERATURE CITED}

Averyanov, L.V. (1994). Identification guide to Vietnamese orchids (Orchidaceae Juss.). S.-Petersburg: World and Family. Averyanov, L. V. \& Averyanova, A. L. (2003). Updated checklist of the orchids of Vietnam. Hanoi: Vietnam National University.

Beentje, H. (2012). The Kew Plant Glossary, an illustrated dictionary of plant terms (revised edition). Kew: Royal Botanic Gardens, Kew Publishing.

Chen S. C. \& Wood, J. J. (2009). Pelatantheria. Pp. 456-457 in: Z. G. Wu, P. H. Raven, Hong D.Y. (eds) Flora of China. Vol. 25. Beijing \& St. Louis: Science Press \& MBG Press.

Govaerts, R., Dransfield, J., Zona, S. F., Hodel, D. R. \& Henderson, A. (2017). World Checklist of Orchidaceae. Facilitated by the Royal Botanic Gardens, Kew. Published on the Internet: http://apps.kew.org/wcsp/ Retrieved 2017-11-21.

Haager, J.R. (1993). Some new taxa of orchids from southern Vietnam. Orchid Digest, 57, 39-42.

O’ Byrne, P. (2009). Three Orchid species named after OSSEA Members. Malayan Orchid Review, 43, 96-105.

Seidenfaden, G. (1992). The Orchids of Indochina. Copenhagen: Council for Nordic Publications in Botany. 
LANKESTERIANA 